\title{
Developing a comprehensive, effective patient-friendly website to enhance decision making in predictive testing for Huntington disease
}

\author{
Alice K. Hawkins Virani, MS, PhD ${ }^{1}$, S.M. Creighton, MS, $\mathrm{CGC}^{1}$ and M.R. Hayden, MB, PhD ${ }^{1,2}$
}

\begin{abstract}
Purpose: Predictive testing for Huntington disease is a complex decision, requiring in-depth counseling, education, and evaluation. Despite the growth in Web-based decision aids and educational resources, such tools for those considering Huntington disease testing are not available. The main objective of this project was to develop a patient-friendly, comprehensive, accessible Web-based tool to provide accurate information about testing for Huntington disease.
\end{abstract}

Methods: A semistructured interview study was conducted to determine the informational, educational, and support needs of those considering Huntington disease testing. A dedicated predictive testing website was subsequently developed and pilot tested.

Results: The interview study revealed that an effective website should include interactive diagrams, video documentaries, and personal stories of others who had considered testing. The pilot test revealed that the multidimensional site was easy to navigate and understand and provided an accurate, unbiased overview of the important factors to be considered before undergoing predictive testing.

Conclusion: This project demonstrates the use of a mixed-method approach to develop the first tailored website dedicated to predictive testing for Huntington disease. Such an approach enabled the development of a comprehensive, accurate, and effective educational tool that supports informed decision making for people considering predictive testing for Huntington disease in an accessible, nonthreatening manner.

Genet Med 2013:15(6):466-472

Key Words: decision making; Huntington disease; predictive testing; Web-based learning; website development

\section{INTRODUCTION}

Huntington disease (HD) (OMIM no. 143100) is a dominantly inherited progressive neuropsychiatric disease caused by a CAG triplet repeat expansion mutation in the huntingtin gene. ${ }^{1} \mathrm{HD}$ predictive testing (PT) has been available via linkage since 1986 and by direct mutation analysis since $1993 .{ }^{2}$ Although there is currently no treatment, testing affords some at-risk individuals benefits such as relieving uncertainty and providing information to make decisions around reproductive choices and financial and insurance planning. ${ }^{3,4}$ Testing uptake rates among those at 50\% risk of developing the disorder vary widely, with estimates ranging from $5 \%$ to $25 \%$, depending on the calculation methods used. ${ }^{5,6}$

PT for the disorder is recognized as being an irreversible decision of great consequence, with psychological and emotional implications such as guilt (including "survivor guilt"), shame, fear, and other effects such as unintentional risk alteration for biological relatives. ${ }^{7-9}$ As such, the international guidelines for HD PT recommend that individuals considering testing undergo in-depth genetic counseling, psychosocial evaluation, and assessment to ensure they have adequate support and are prepared for receiving this news. ${ }^{10}$ Despite considerable concern about possible adverse events following predictive test results, these fears do not appear to have been realized. Instead, the majority of studies suggest that people are satisfied with their decision to be tested and cope well when adequately prepared to receive an $\mathrm{HD}$ test result. ${ }^{11-14}$

The decision to proceed with PT may be dynamic and may unfold over time or it may be more automatic or triggered by a particular event. ${ }^{15}$ It is shaped by clinical or sociopolitical contexts (e.g., test accessibility and availability, cost, psychiatric diagnoses), as well as other personal and familial factors. ${ }^{16}$ Providing adequate support during this process entails nondirective counseling to allow individuals to consider the pros and cons of such testing and make up their own minds as to whether testing is right for them. ${ }^{17}$ To aid in the provision of such nondirected, supported decision making, at-risk individuals should be provided with factual information on the testing process and its ramifications. One-on-one genetic counseling and education with an appropriately trained professional is a fundamental part of the informed consent process in $\mathrm{PT} .{ }^{18}$ However, it is difficult to provide such counseling as it is time consuming and expensive, and there are a limited number of genetics professionals qualified to provide such services. ${ }^{19,20}$ Such counseling may also not be easily available due to a number of access barriers including distance, travel time, and availability of support. ${ }^{21}$ Moreover, the possibility of clinical trials for those at risk may mean that more people will consider PT for the disorder in the future.

${ }^{1}$ Centre for Molecular Medicine and Therapeutics, University of British Columbia, Child and Family Research Institute, Vancouver, British Columbia, Canada; ${ }^{2}$ Department of Medical Genetics, University of British Columbia, Vancover, British Columbia, Canada. Correspondence: Alice K. Hawkins Virani (alicehaw@exchange.ubc.ca) 
As such, there is an imperative to develop effective and accessible tools to aid in the informed decision-making process for those considering predictive genetic testing. Previous research has demonstrated the importance and effectiveness of written and Web-based tools in supporting complex health-care decisions. ${ }^{22}$ These materials may be Web or CD based and include diagrams, interactive flowcharts, decision-making trees, vignettes or personal stories, and short videos/cartoons of health-care providers or patients discussing their experience. ${ }^{23}$ However, the use of such decision aids and websites in genetic testing is mainly confined to the hereditary cancer field. ${ }^{24,25}$ Although some educational written and Web-based resources for HD PT exist, these resources are often within websites providing information on HD in general and do not include multiple presentation methods, including diagrams, documentaries, and narratives thought to be effective in communicating information and promoting informed decision making to a wide audience because they account for differences in learning and information processing styles. ${ }^{25-28}$

The main objective of this project was to develop a patientfriendly, comprehensive, accessible Web-based tool to provide accurate information about PT for HD. The aim of this website was to provide a reliable source of information to individuals at risk for the disorder and their loved ones, in addition to support and resources that may be useful when considering PT for HD. To ensure this educational resource would meet future users' needs, this project involved a mixed-methods approach including a literature and existing resource review, and an interview study of those at risk for developing HD, followed by the development, pilot test, and modification of the website.

\section{Interview study}

\section{MATERIALS AND METHODS}

The first part of this project involved a semistructured interview study to gain an understanding of appropriate content and format of a website geared toward predictive test decision making. Recruitment was based on a nonprobability sample in which participants were identified based on convenience and accessibility. Recruitment sought to obtain a varied sample of atrisk individuals, including those who had not been tested and those who had been tested (and received either an increased risk and decreased risk results). Potential interview participants were identified using the Huntington Society of Canada, British Columbia (BC) Chapter database, and the Centre for HD (Vancouver) database. Interested participants returned a consent form to the investigators before the interview was scheduled. Research ethics approval was obtained for this study.

A total of 33 participants were asked a series of open-ended questions regarding their perspective on PT, their decisionmaking process surrounding $\mathrm{PT}$, important considerations and components in the decision-making process, and education/information needs when considering PT. Interviews lasted 45-60 min and each interview was recorded (with permission), transcribed, and subjected to a content analysis ${ }^{29}$ with the aid of qualitative analysis software (nvivo 9; QSR International, Burlington, MA). Data collection and analysis occurred concurrently, using the constant comparative method ${ }^{30,31}$ so that concepts, themes, and ideas that emerged from the analysis could be incorporated into later interviews to allow for a more detailed understanding of key issues to be developed. The interview and analysis process was conducted until theoretical saturation was achieved (i.e., no new data or insights were revealed by subsequent interviews). ${ }^{31,32}$

\section{Website development}

On the basis of the results of the interview study (described later in the text), a review of the existing resources and published literature on decision making, and the development of successful health-related resources, we created a website dedicated to PT for HD. Website content was developed using existing materials from the Centre for HD in Vancouver and from the Huntington Society of Canada resources on PT. These resources were reviewed by the authors and supplemented, updated, and modified to improve consistency and comprehensibility and also to ensure they met the content needs determined from the interview study results. Interactive diagrams and images to explain complex topics, such as the CAG repeat size and results, were developed, tested, and modified based on feedback from other HD researchers, genetic counselors, and laypeople (Figure 1). Four short video documentaries were developed on the following topics: (i) the decision to undergo PT; (ii) interpreting and understanding predictive test results; (iii) coping with results; and (iv) HD research. These topic areas were chosen based on the focus of the website (to help individuals understand the decision to undergo PT) and the results of the interview study (discussed in the next section).

Stories for the website came from a variety of different sources including a series of in-depth research interviews as well as those that were submitted in response to requests for personal perspectives on genetic testing. ${ }^{33}$ The personal reflections contained in the story section were divided into different sections to represent different perspectives on PT including the decision to proceed with testing; the decision not to go through PT; the PT process; and coping with results.

On the basis of the interview feedback, the overall website design and layout aimed to be welcoming, unintimidating, and not institutional. Images were selected for diversity and to highlight the familial aspect of the condition. Photos on the site aimed to convey an overall tone to website users that a friend or close relative was welcoming them to discuss testing. All aspects of website design, including layout, diagrams, content, and documentary/diagram development, were based on established principles in successful Web-based education and decision-facilitation tools. ${ }^{23,34-36}$

Once the website was live and fully operational, a pilot test of the site was conducted to evaluate the content and test usability. A short Web-based survey was sent to 35 select individuals who had participated in the interview study $(n=10)$, genetic counselors across North America $(n=5)$, HD researchers and HD experts $(n=10)$, and lay individuals $(n=10)$. Pilot test respondents were recruited based on 


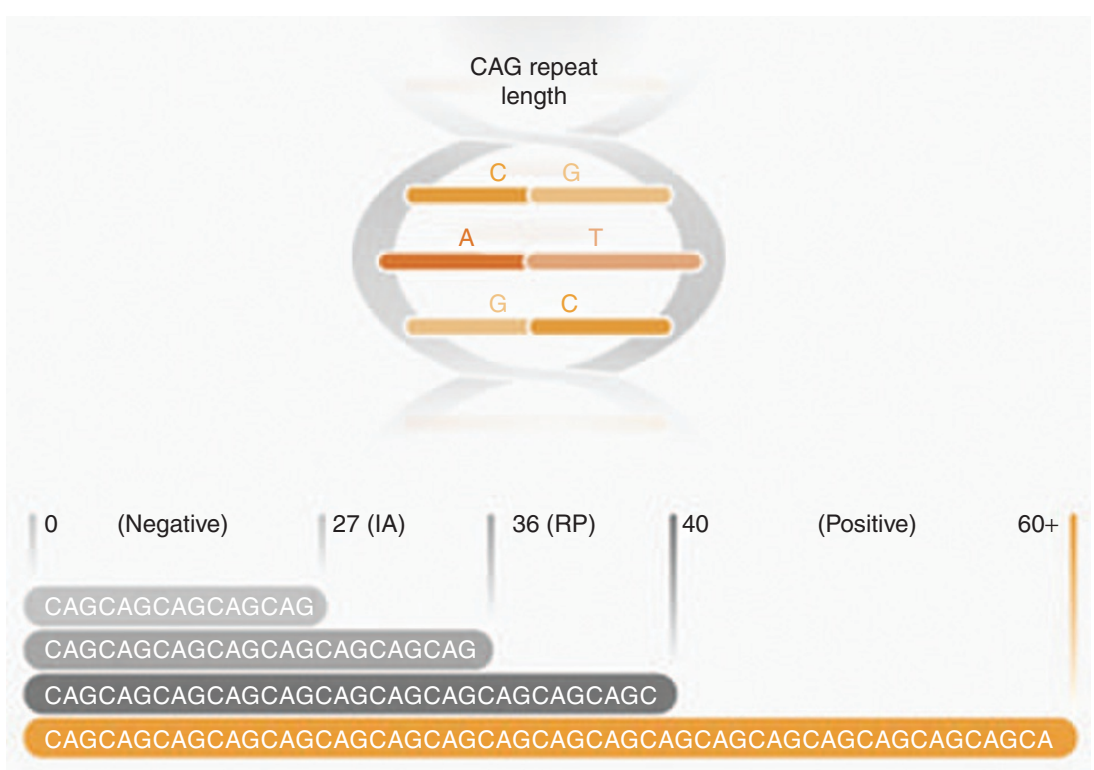

Figure 1 Website diagram describing CAG repeat sizes.

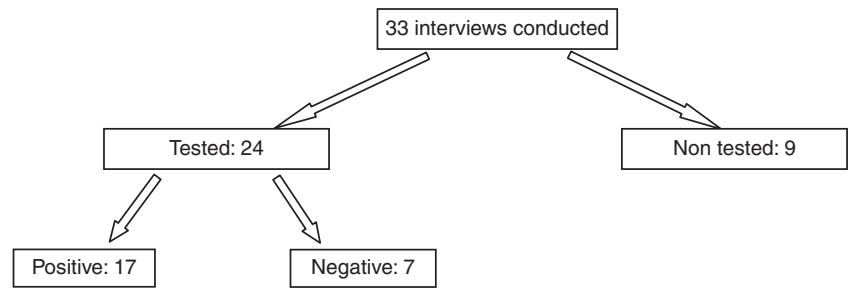

Figure 2 Predictive testing status of those who participated in the interview study.

availability, convenience, and snowball sampling. These individuals received an e-mail inviting them to view the website and participate in a short Web-based survey consisting of a series of closed-ended questions regarding the website content, usability, comprehensiveness, language level, diagrams, images, and documentaries. Respondents were encouraged to provide comments and explain each of their responses, as well as to provide suggestions for improvement. Each of these comments was reviewed several times in detail and coded for themes. Similar concepts or ideas were grouped into the same category to allow for an understanding of the diversity in the comments received, as well as nuanced details and perspectives on certain issues. ${ }^{32}$

\section{RESULTS}

\section{Interview findings}

A total of 33 individuals participated in the interview study (Figure 2). Results of the interview study revealed overwhelming support for a Web-based resource to be developed that was specific to PT for HD. Direct quotations from interview participants presented in the discussion section illustrate specific themes that were voiced.

Interview participants noted that when people need information on a particular topic, often the first place that they would turn to was the Internet: "A lot of people's first place of looking (sic) for answers when they have questions is the Internet." Another respondent highlighted that this is particularly important for those who are in more remote or rural locations and who cannot easily access resources in person: "Having it [a predictive testing resource] online is a great idea-especially when people are remote." Ensuring accessibility of resources also helps people who "want to reach out, they just don't know how." Respondents also noted that the websites that existed on HD were often geared toward individuals or caregivers who had recently been informed of a HD diagnosis in their family. Although these websites were helpful, they were also perceived as "scary" and "intimidating" and they were not necessarily easy to navigate.

A key finding from the interview study was the importance of personal stories and perspectives in making it easier for people to determine whether or not PT is the right choice for them and to explore "the pros and cons." As one participant explained: "I had a niece call me just a few months ago because of my decision not to be tested. She called me and she was calling the other one [aunt] that had tested and had been tested negative. Anyways, she's at that stage... . She's a young girl deciding on a family and she's at that stage and that's what she was looking for ... the stories. Why did you choose what you chose?" Other participants emphasized the importance of hearing the story of someone who had been in a similar position, as there was a shared understanding and experience with such individuals, which could not be found in friends or family members not at risk for HD: "People want to know. They do want to say "what was it like for you?" Unless you're carrying the gene or not carrying the gene, it's hard to convey the magnitude of it to someone else."

Participants also noted that personal perspectives and stories were important in helping people feel less alone and isolated 
in their experience and risk of developing HD: "Sometimes Huntington's feels like such a lone disease. Not a lot of people still know about it and, you know, you can feel like you're struggling all by yourself. [A website] just makes more people less alone, I think." Others highlighted the importance of other peoples' stories and perspectives of going through the process and receiving results: "If there was [somewhere] that I could read of people's experiences and kind of see how people dealt with things. Everybody has a different story and different situations you know ... just kind of feeling like you are not going through some big huge hospital, wandering down a hallway where you don't even know you are going and then all of a sudden you have these amazing huge results, you know ... so feeling like you are kind of alone, I guess." One participant also spoke of existing HD blogs that she had read, and that these blogs had offered her a sense of comfort: "Certainly there have been times where it's nice ... to know there's a group of people [out there] and sometimes I've just gone on there to read people's stories and get a sense of not being alone in things."

In addition to emphasizing the importance of personal stories from others at risk, interview respondents identified several other key components of a successful website on PT. These included information on the genetics and inheritance of HD, including concepts such as new mutations and reduced penetrance; steps in the PT process; information on where testing could be done/how to get tested; diagrams, videos, and pictures that supplemented text to aid in understanding of concepts; a detailed discussion of the decision-making process involved in determining whether PT was the right choice; a description of the different test results (i.e., positive, negative, reduced penetrance, and intermediate alleles) and coping with results; prenatal and other reproductive testing options; and links to other HD-related resources and local support groups. As one respondent suggested: "If there was a site that was family friendly and had lots of good information and the hard-core research-a little bit for everybody-I think people wouldn't be so scared." Many participants also noted that a section on HD-related research would be helpful, especially for those who received a positive test result, even though this was not the primary goal of the site. Finally, respondents suggested that information geared toward family members/friends of those at risk for the disease would be important given that these individuals were often integral to the decision of whether or not to undergo PT.

The findings from the interview study detailed above were used to inform all stages of the website development from the overall look and feel of the site to the content and flow of the website.

\section{Pilot test results}

Of 35 potential participants, 23 completed the website pilot test survey for a response rate of $65.7 \%$. The characteristics of these respondents are outlined in Figure 3. A collation of survey responses revealed that all of the respondents agreed that the website was clearly laid out and easy to navigate. Comments

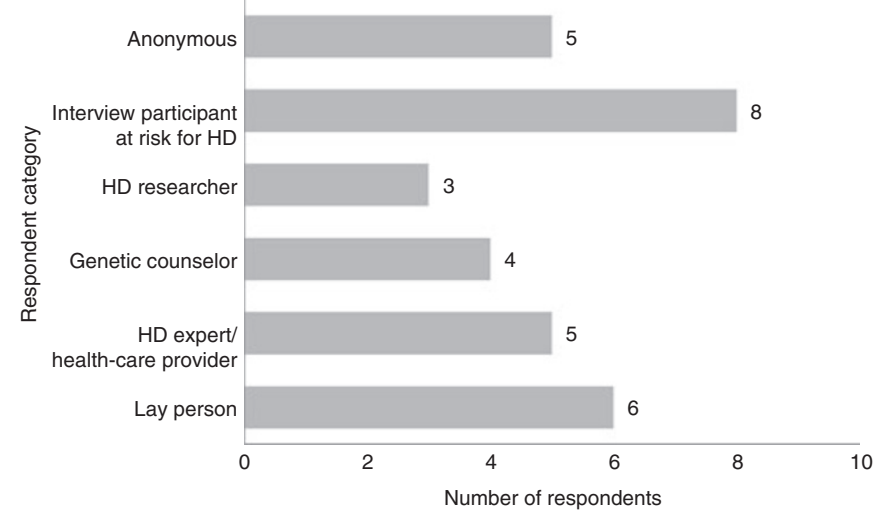

Figure 3 Characteristics of those who participated in the website pilot test. HD, Huntington disease.

received included: "One of the best-organized and clear websites I have visited" and "It was really well laid out and beautifully designed." Suggestions for improvement included modifying the hover menus so they would work on touch screen devices (such as iPads), creating a separate section on prenatal testing/reproductive testing options, and creating a "userguide" to the website for those who were not familiar with drop-down menus.

Participants were also asked whether the content of the website was clear and easy to understand. Again, the majority ( $n=22 / 23,96 \%)$ of respondents answered "yes" to this question, and made comments such as "I was very impressed with how the site's information is organized and laid out ... the language is at a good level for many to understand" and "I thought it really covered everything very well. I honestly could not think of anything that would be lacking at this point." Suggestions for improvement in the content included editing of some of the sections that were too text heavy; reordering of subheadings to make them more intuitive; making the "Research Updates" section more succinct; and slowing down the speed at which the images and text on the home page moved.

The next question focused on the illustrations and diagrams developed specifically for the website, which, for example, depicted the HD inheritance process; genes, chromosomes, and DNA; and the different categories of CAG repeat sizes. All but one $(n=22 / 23,96 \%)$ of the respondents thought the diagrams and illustrations on the site were helpful. Respondents also thought that the "diagrams on genetics [were] useful and very clear and easy to understand without reading [the] explanation." One respondent, an HD researcher, indicated that the diagrams would be useful for laypeople and that it would be a useful resource for other family members to understand the disease: "I feel like I should give my parents this link so they can better understand what I'm working on." Suggestions for improvement included clarifying that HD can be passed down from either a mother or father (the diagram depicted the mutation being inherited from the father) and having more diversity in the photos on the site. 


\section{Table 1 Website pilot test survey results}

\begin{tabular}{l} 
Question \\
$\begin{array}{l}\text { Percentage of responses } \\
\text { that were positive in } \\
\text { nature (as indicated by a } \\
\text { "yes" response) }\end{array}$ \\
\hline $\begin{array}{l}\text { Is the website clearly laid out and easy } \\
\text { to navigate (find your way around)? }\end{array}$ \\
$\begin{array}{l}\text { Is the content of the website clear and } \\
\text { easy to understand? }\end{array}$ \\
$\begin{array}{l}\text { Are the illustrations and diagrams } \\
\text { helpful? }\end{array}$ \\
$\begin{array}{l}\text { Does the website provide adequate } \\
\text { information on "what is HD"? }\end{array}$ \\
$\begin{array}{l}\text { Does the website provide adequate } \\
\text { information on "testing for HD"? }\end{array}$ \\
$\begin{array}{l}\text { Does the website provide enough } \\
\text { information on the pros and cons of } \\
\text { testing and making the decision to be } \\
\text { tested? }\end{array}$ \\
\hline
\end{tabular}

HD, Huntington disease.

Respondents were then asked to consider whether the website provided adequate information on "what is HD?" and "testing for HD." All respondents thought there was adequate information on the first of these, and 91\% ( $n=$ 21/23) of respondents felt there was adequate information on the PT process. In particular, respondents "loved" the use of stories that were felt to be "very powerful" and "unbiased" given that they provided a wide variety of perspectives on PT. Respondents also particularly liked the "Important Considerations" section for undergoing HD PT. Suggestions for improvement included wording changes to improve clarity and accuracy of the descriptions, providing further links for resources, and adding more detail to the section on how testing is done.

Similarly, respondents were also asked to consider whether the website provided adequate information on the "pros and cons" of PT. All respondents agreed that the website did provide adequate information on this topic as illustrated by the following comments: "It does a good job of explaining what the test process is and questions to ask oneself"; "The testing is presented in a very unbiased way. It should give people some excellent issues to consider"; and "As a website you could not do much more." Again, people highlighted the importance of the stories in this regard: "I got most pros/cons for testing from stories. Stories [were] long but very powerful." Suggestions to improve this section were limited and included a proposal to include video clips of individuals discussing their reasons for and against pursuing PT.

The final section of the survey encouraged respondents to provide other comments and suggestions regarding the website. Suggestions for improvement included changing the font and text spacing on the site to improve readability; addressing "technical glitches" with the site, including difficulty viewing the site on different operating systems; and minor editing suggestions. Other comments received indicated general overall support for the site: "The site is [a] very important tool for people who need it"; "I can't think why we've not done this before now"; "I am impressed with this work, and would definitely refer patients to this website for accurate information and good support examples"; and "[The] website is clear, concise, beautiful, and you have done an impressive job. With a few little "tweaks" you will be able to confidently launch this wonderful and very informative website." A summary of the results is provided in Table 1 .

\section{DISCUSSION}

This project illustrates the importance of a multimethod approach to developing educational resources. This methodology included an extensive review of existing resources; an exploration of the literature on patient education and website development; interviews with people at risk for $\mathrm{HD}$ and with experts in PT; and the development and pilot testing of a website. This process drew on established methods to develop successful educational/informational tools to develop a site that would promote informed, supported decision making. For example, the preference for narratives is supported by empirical studies on patients' needs and desires whereby people seek others' stories to help them deal with difficulty and feel comforted that they are not alone in their situation. ${ }^{28,37}$ Such narratives are key in helping people cope with difficult information, particularly among those with low literacy skills. ${ }^{38}$ Stories can add salience to information, and help make facts and key considerations more understandable. ${ }^{27}$ Moreover, these narratives can assist in the decision-making process by prompting people to reflect and consider their options more carefully, thereby, helping them to make a truly informed decision. ${ }^{39}$ When constructing the website, particular attention was paid to presenting a balanced and diverse set of stories and perspectives about why people chose to have PT, or chose not to, and what the experience of the decision making and testing process was like for them. Narratives, therefore, represented a broad range of perspectives to avoid the potential criticism of bias in these stories, which may, in turn, bias decision making. ${ }^{38,40}$ Pilot study responses commended the balanced nature of these stories, suggesting that the selection of stories and diverse viewpoints provided a considered and unbiased set of perspectives for the reader to consider.

In addition, where possible and appropriate, suggestions for improvement received from the pilot study were incorporated into the website. For example, technical issues were resolved, headings and fonts were amended to improve comprehensibility, certain subsections were moved or reordered to improve intuitive flow of the website, and content was amended to enhance understanding. In addition, several features were integrated into the website to account for different audience needs, such as enabling text size to be changed to a larger font to assist those with visual impairments. It is possible that pilot test respondents may have been somewhat biased in that they may have known the researchers, and by responding to the survey they may have self-selected to be 
inherently supportive of such a website. However, honest review and feedback and candid critique was encouraged by making the survey anonymous and by distributing the pilot study widely. The primarily positive responses received may also reflect the thorough and considered initial website development process, which integrated interview findings, use of existing successful resources, and significant evaluation and number of iterations of the website before pilot release.

By taking such a comprehensive, needs-assessment approach to website development, we developed a site that is specifically tailored to the needs of those considering PT. The site acts as a guide and reliable information source throughout the testing process, including the postresult period. The site has the potential to truly provide support and assistance for those making the decision of whether or not to undergo PT. The design and content of the site, as well as the portability of Web-based resources, allow individuals to obtain and explore information in an accessible, nonthreatening manner. Such a site also improves access to reliable information, local resources, and support. As illustrated by the interview study and prior research, ${ }^{21}$ this resource is particularly valuable for individuals who live in remote or rural locations. To further improve access to reliable information in other areas, the site is currently being translated into 12 other languages. The site can also be used in conjunction with telehealth methods to improve access to PT for HD. ${ }^{21}$ In conclusion, further work and evaluation are needed to evaluate the utility of the site for those undergoing the PT process. This could include pre- and postmeasures to evaluate uptake of accurate information and satisfaction with the site on a variety of levels including usability, utility, and comprehensibility.

\section{ACKNOWLEDGMENTS}

We are grateful to those who participated in the interview study and the website study for sharing their thoughts, experiences, and opinions with us. Funding for the research and the website development was provided by CHDI.

\section{DISCLOSURE}

The authors declare no conflict of interest.

\section{REFERENCES}

1. MacDonald ME, Ambrose CM, Duyao MP, et al. A novel gene containing a trinucleotide repeat that is expanded and unstable on Huntington's disease chromosomes. Cell 1993;72:971-983.

2. Kremer B, Goldberg P, Andrew SE, et al. A worldwide study of the Huntington's disease mutation. The sensitivity and specificity of measuring CAG repeats. $N$ Eng/ J Med 1994;330:1401-1406.

3. Wiggins $S$, Whyte $P$, Huggins $M$, et al. The psychological consequences of predictive testing for Huntington's disease. N Engl J Med 1992;327:14011405.

4. Harper PS, Lim C, Craufurd D. Ten years of presymptomatic testing for Huntington's disease: the experience of the UK Huntington's Disease Prediction Consortium. J Med Genet 2000;37:567-571.

5. Creighton S, Almqvist EW, MacGregor D, et al. Predictive, pre-natal and diagnostic genetic testing for Huntington's disease: the experience in Canada from 1987 to 2000. Clin Genet 2003;63:462-475.

6. Tassicker RJ, Teltscher B, Trembath MK, et al. Problems assessing uptake of Huntington disease predictive testing and a proposed solution. Eur J Hum Genet 2009;17:66-70.
7. Bloch M, Adam S, Wiggins S, Huggins M, Hayden MR. Predictive testing for Huntington disease in Canada: the experience of those receiving an increased risk. Am J Med Genet 1992;42:499-507.

8. Wiggins $S$, Whyte $P$, Huggins $M$, et al. The psychological consequences of predictive testing for Huntington's disease. Canadian Collaborative Study of Predictive Testing. N Engl J Med 1992;327:1401-1405.

9. Benjamin $\mathrm{CM}$, Adam S, Wiggins $\mathrm{S}$, et al. Proceed with care: direct predictive testing for Huntington disease. Am J Hum Genet 1994;55:606-617.

10. Macleod R, Tibben A, Frontali M, et al. Recommendations for the predictive genetic test in Huntington's disease. Clin Genet 2012;9999.

11. Hayden MR. Predictive testing for Huntington's disease: the calm after the storm. Lancet 2000;356:1944-1945.

12. Dufrasne S, Roy M, Galvez M, Rosenblatt DS. Experience over fifteen years with a protocol for predictive testing for Huntington disease. Mol Genet Metab 2011;102:494-504

13. Decruyenaere M, Evers-Kiebooms G, Cloostermans T, et al. Psychological distress in the 5-year period after predictive testing for Huntington's disease. Eur J Hum Genet 2003;11:30-38.

14. Meiser B, Dunn S. Psychological impact of genetic testing for Huntington's disease: an update of the literature. I Neurol Neurosurg Psychiatr 2000:69:574-578.

15. Etchegary H. Genetic testing for Huntington's disease: how is the decision taken? Genet Test 2006;10:60-67.

16. Taylor SD. Predictive genetic test decisions for Huntington's disease: context, appraisal and new moral imperatives. Soc Sci Med 2004;58:137-149.

17. Elwyn G, Gray J, Clarke A. Shared decision making and non-directiveness in genetic counselling. J Med Genet 2000;37:135-138.

18. Green MJ, Biesecker BB, Mclnerney AM, Mauger D, Fost N. An interactive computer program can effectively educate patients about genetic testing for breast cancer susceptibility. Am J Med Genet 2001;103:16-23.

19. Holtzman N, Watson M. Promoting Safe and Effective Genetic Testing in the United States: Final Report of the Task Force on Genetic Testing. Johns Hopkins University Press: Baltimore, MD, 1998.

20. Edwards J, Greenberg J, Sahhar M. Global awakening in genetic counseling. Nature Precedings http://hdl.handle.net/10101/npre.2008.1574.1. 2008.

21. Hawkins AK, Creighton S, Hayden MR. When access is an issue: exploring barriers to predictive testing for Huntington disease in British Columbia, Canada. Eur J Hum Genet 2012; e-pub ahead of print 11 July 2012.

22. O'Connor AM, Rostom A, Fiset $V$, et al. Decision aids for patients facing health treatment or screening decisions: systematic review. BMJ 1999; 319:731-734

23. Cook DA, Dupras DM. A practical guide to developing effective web-based learning. J Gen Intern Med 2004;19:698-707.

24. Green MJ, Peterson SK, Baker MW, et al. Use of an educational computer program before genetic counseling for breast cancer susceptibility: effects on duration and content of counseling sessions. Genet Med 2005;7:221-229.

25. Wang C, Gonzalez R, Milliron KJ, Strecher VJ, Merajver SD. Genetic counseling for BRCA1/2: a randomized controlled trial of two strategies to facilitate the education and counseling process. Am J Med Genet A 2005;134A:66-73.

26. Green MJ, Peterson SK, Baker MW, et al. Effect of a computer-based decision aid on knowledge, perceptions, and intentions about genetic testing for breast cancer susceptibility: a randomized controlled trial. JAMA 2004;292:442-452

27. Ziebland S, Herxheimer A. How patients' experiences contribute to decision making: illustrations from DIPEx (personal experiences of health and illness). J Nurs Manag 2008;16:433-439.

28. Trees AR, Koenig Kellas J, Roche Ml. Family narratives. In: Gaff CL, Bylund CL, (eds). Family Communication About Genetics: Theory and Practice. Oxford University Press: New York, 2010.

29. Corbin J, Strauss A. Basics of Qualitative Research: Techniques and Procedures for Developing Grounded Theory. Sage Publications: Thousand Oaks, CA 2008.

30. Glaser BG. The constant comparative method of qualitative analysis. Soc Prob/ 1965; 12:436-445.

31. Boeije $\mathrm{H}$. A purposeful approach to the constant comparative method in the analysis of qualitative interviews. Qual Quant 2002;36:391-409.

32. Creswell J. Research Design: Qualitative, Quantitative, and Mixed Method Approaches, 2nd edn. Sage Publications: Thousand Oaks, CA, 2003.

33. Cox S. Personal Perspectives on Genetic Testing for Huntington Disease. Huntington Society of Canada: Kitchener, Canada, 1999.

34. Stout PA, Villegas J, Kim H. Enhancing learning through use of interactive tools on health-related websites. Health Educ Res 2001;16:721-733. 


\section{EDUCATION REPORT}

35. Lipkus IM. Numeric, verbal, and visual formats of conveying health risks: suggested best practices and future recommendations. Med Decis Making 2007;27:696-713.

36. Lea DH, Kaphingst KA, Bowen D, Lipkus I, Hadley DW. Communicating genetic and genomic information: health literacy and numeracy considerations. Public Health Genomics 2011;14:279-289.

37. Rozmovits L, Ziebland S. What do patients with prostate or breast cancer want from an Internet site? A qualitative study of information needs. Patient Educ Couns 2004;53:57-64.
HAWKINS VIRANI et al | To enhance decision making in predictive testing for HD

38. Butow P, Fowler J, Ziebland S. Section 5: Using personal stories. In: O'Connor A, Llewelyn-Thomas H, Stacey D. (eds). IPDAS International Collaboration Document, International Patient Decision Aids Standards (IPDAS) Collaboration http://www ipdas.ohri.ca/IPDAS_Background.pdf. 2005:24-27.

39. Entwistle VA, France EF, Wyke S, et al. How information about other people's personal experiences can help with healthcare decision-making: a qualitative study. Patient Educ Couns 2011;85:e291-e298.

40. Winterbottom A, Bekker HL, Conner M, Mooney A. Does narrative information bias individual's decision making? A systematic review. Soc Sci Med 2008:67:2079-2088. 